\title{
Obesity Prevention Strategies for Teenage Adults in Central and Eastern Europe
}

\section{J. Robinson (Justin Robinson), S. Szydlowski (Steven Szydlowski)}

University of Scranton, PA., Master of Health Administration Graduate Program, USA

\section{E-mail address:}

justin.robinson@scranton.edu

\section{Reprint address:}

Justin Robinson

University of Scranton

Scranton Hall

Scranton, PA. 18510

USA

Source: Clinical Social Work and Health Intervention

Pages: $39-43$
Volume: 10

Issue: 1

\section{Reviewers:}

Gunther Dorfmeister

Vienna General Hospital, Vienna, Austria

Jirina Kafkova

Nairobi, St. Bakitha Clinic, Kenya

\section{Key words:}

Obesity. Prevention Strategies. Slovakia. Czech Republic. Risks. Solutions.

\section{Publisher:}

International Society of Applied Preventive Medicine i-gap

CSWHI 2019; 10(1): 39 - 43; DOI 10.22359/cswhi_10_1_06 @ 2019 Clinical Social Work and Health Intervention

\section{Abstract:}

Objective: This research paper discusses the obesity problem affecting the younger population in Central and Eastern Europe. Through analyzing information from the World Health Organization (WHO) and other realizable sources, current and future prevention strategies are examples alone with the potential health risk factors presented by being obese. 
Methods: This paper is a secondary resource of obesity in the younger adult population in Central and Eastern Europe, with strategies to decrease the effects on these individuals.

Results: The Central and Eastern European countries of Slovakia, Czech Republic, Hungary, and Poland should expand the knowledge of assisting younger adults on the importance of understanding healthy eating habits as well as incorporating physical activity into their daily lifestyle.

Conclusion: This research shows the need to increase the demand for educating and providing support services for the younger population. The importance of healthy eating and the risk associated with lack of exercise caused by unhealthy habits in Slovakia, Czech Republic, Hungary and Poland.

\section{Introduction}

Almost every country around the world has experienced some form of obesity in their population. The key to overcoming these issues and preventing a widespread epidemic is knowing how to prevent these measures before it increases. Obesity is having a body mass index (BMI) greater than 25, which is determined by the body mass of an individual divided by the square of their body height, known as the greater weight to height ratio. Obesity is becoming one of the greatest challenges in public health in Europe. Currently is responsible for $2-8 \%$ of health cost and 10-13\% of deaths throughout the European region (World Health Organization, n.d.).

\section{Demographics}

The obesity rate in the European countries of Slovakia, Czech, Hungary and Poland continues to rise. A 2016 study showed obesity notes for the population of young 18 year olds and older male and females as follows: Slovakia $21.0 \%$ males and $19.9 \%$ females; Czech Republic 26.4\% in males and $25.4 \%$ in females; Hungary $28.2 \%$ males and 24.6\%females; Poland 23.7\% males and $22.2 \%$ females (Knoema, 2016).
The 2016 statistics showed the Czech Republic and Hungary as having the most individuals of male and female falling into the obesity category. The numbers in the Czech Republic, Hungary and Poland are showing a decrease in their percentage of obese individuals, but Slovakia is still showing an increase at an annual rate of $2.4 \%$ each year in their male community if proper prevention measures are not performed.

Some important factors contributing to the increase in weight for individuals has socially, personally, and environmental determinants. The key concerns are mostly being led by: lack of physical activity being conducted by the younger population; being introduced to bad eating habits early in life; lack of educational knowledge to distinguish unhealthy and healthy food options; lack of resources available locally to choose healthy foods.

Obesity has many potential risk factors associated with being overweight. The leading concern in Central and Eastern Europe as a result of being obese is Diabetes. According to the WHO, 80\% of all type 2 diabetes cases were associated with obesity; 55\% were related to hypertension; 
$35 \%$ contributing to cardiovascular disease. Obesity is also considered as the 5th leading death risk. Personal risk also plays an important role in the younger population. Being obese can produce low self-esteem, depression and reduce confidence.

The projected obesity rate for 2030 has the Czech Republic nearly doubling its obesity rates in the years to come. Slovakia and Poland are expected to increase quite similar to one another. It is estimated by the European commission that obesity contributes to $7 \%$ of the total health care expenditure (around 81 billion euros per year). Obesity contribute to an increase in the diabetes costing health care around $10 \%$ of their expenditure and is expected to increase to $17 \%$ by 2030 if preventative measures are not conducted. The total cost of diabetes being treated is around 300 million euros per year with an expected increase of approximately $1 \%$ every 3 years. If this current trend continues, it is expected that obesity will impact 15 million people or $10 \%$ of European younger adults being considered overweight. Only Hungary is expected by the World Health Organization to slowly decrease obesity numbers in the younger population by 2030 .

\section{Slovakia vs Czech Republic Intervention Comparison}

The comparison of Slovakia and the Czech Republic in terms of intervention policies and action plans currently in place to reduce the obesity rate are quite similar to one another, but still have improvements and differences presented by both countries in how they are handling their obesity prevention methods. Slovakia is incorporating different polices and plans to cut the intake of the types of unhealthy food choices their younger generation is consuming. In doing so, they are partnering with professional networks in providing health-enhancing physical activity guidance, and the proper education to be aware of their healthy choices. Also, developing marketing policies on being able to cut the high fats, salt and sugar (HFSS) consumption in their teen population. The Czech Republic is producing similar interventions, but with limited consumer awareness and their inability to develop a policy to assist in the high fats, salt and sugar consumption in regards to their teen community. Additional interventions both countries could incorporate to aid in these strategies, would be to further educate and discuss the potential health risks associated with lack of exercise and unhealthy eating. Informing the younger community prior to their full adulthood could reduce future risk and even encourage young people to change their habits and gain a healthier livelihood.

\section{Obesity Prevention Strategies}

Prevention is key to aiding in the health of our younger population. Slovakia, the Czech Republic, Hungary and Poland have all provided their own strategies to prevent and aid in the decrease of preventing further obese individuals. Slovakia's strategies are: conducting regulations on the advertising of unhealthy food options through social networks such as TV, internet, or radio broadcast. Partnering with local or professional networks to increase physical activity produce proper learning techniques or technology advancements for younger adults to learn the importance of how to read food labels and distinguish the difference in appropriate foods. Teaching younger adults about the certain types of foods they consume can have an impact on their future livelihood.

The Czech Republic strategies are: incorporating pricing policies for regulating the consumption of healthy foods, which would tax unhealthy options and allow tax breaks for healthy choices; placing restrictions highly on processed foods and beverages 
with high sweetener content. Strategies include reducing the current inactive status of the population; increasing physical activity; increasing consumer awareness through seminars and the mass media advertising on the importance of healthy lifestyles.

Hungary have incorporated the Public Health Product Tax to reduce the consumption of unhealthy choices, having higher cost prices on sweetened or unhealthy products would lead to an individual to cut these and encourage healthy options. The path Hungary has taken in this product tax has reduced consumption of unhealthy foods by $16-28 \%$.

Poland is expanding the regulations on meals; controlling portion sizes with clear document- ation of food labelling key to impacting obesity rates in the young population. Incorporating the expansion of health care coverage for obesity treatment; through weight management meetings; educational classes; medications to assist in preventing any further future increase in the obese population.

\section{Conclusions and Recommendations}

The projection for overcoming obesity risk includes changing eating habits and increasing exercise. Incorporating the public health product tax which tax's unhealthy foods forcing teens to choose more healthy options. Increasing the amount of daily physical activity and monitoring nutritional intake is key to dieting and overall weight control. Lastly, having the knowledge and education to teach younger adults proper health choices and understanding how the choices of foods impact future health and lifestyles.

This research emphasizes the effects of obesity while focusing on teenage adults in Central and Eastern Europe, especially in Slovakia, Czech Republic, Hungary and Poland. The key takeaway from this research is the increase in demand for educating and providing support services for the younger population to know the importance of healthy eating and the risk associated with lack of exercise caused by unhealthy habits. The interventions currently in place require further research. Other action plans include reducing salty, sugary and fatty foods which encourages individuals on a financial budget to choose healthy options because of incorporating the new tax policy on unhealthy foods. The action plans of enhancing physical activity will drastically drop the obesity percentage by incorporating some physical involvement in their everyday lifestyles.

\section{References}

1. COHEN S (2017) Obesity in the U.S. and Europe on the Rise: A Comparison. HUFFPOST. Retrieved from https://www.huffingtonpost.com/sam-cohen/obesity-in-the-usand-eur_b_9845182.html.

2. BRANDT L, ERIXON F (2013) The Prevalence and Growth of Obesity and Obesity-related Illnesses in Europe. European Centre for International Political Economy (ECIPE).

3. HUNT A, FERGUSON J (2014) Health costs in the European Union: how much is related to EDCS? Brussels: The Health and Environmental Alliance, Johnson \& Johnson. (2017). Confronting obesity in Poland, Romania and the Czech Republic. The Economist Intelligence Unit. Retrieved from https://perspectives.eiu.com/sites/default/files/ConfrontingobesityinCEE_0.pdf.

4. KNOEMA (2016) World Data Atlas. Retrieved from Knoema: https://knoema.com/ atlas.

5. LORING B, ROBERTSON A (2014) Obesity and inequities: Guidance for addressing inequities in overweight and obesity. WHO Regional Office for Europe. Retrieved http://www.euro.who.int/data/assets/pdf file/0003/247638/obesity-090514.pdf. 
6. WORLD HEALTH ORGANIZATION (2013) Nutrition, Physical Activity and Obesity. WHO Regional Office of Europe. Retrieved from http://www.euro.who. int/_data/assets/pdf_file/0005/243293/ Czech-Republic-WHO-Country-Profile.pdf?ua $=1$.

7. WORLD HEALTH ORGANIZATION (2013) Nutrition, Physical Activity and Obesity: Slovakia. WHO Regional Office for Europe. Retrieved from http://www.euro.who. int/_data/assets/pdf_file/0018/243324/Slovakia-WHO-Country-Profile.pdf?ua=1.

8. WORLD HEALTH ORGANIZATION (2013) July 4. Towards a new milestone in European nutrition and physical activity policies. Retrieved from World Health Organization: Regional Office for Europe: https://www.slideshare.net/who_europe/towards-a-new-milestone-in-european-nutrition-and-physical-activity-policies.

9. CEPOVA E, KOLARCIK P, MADARASOVA GECKOVA A (2017) Health literacy, method as improve health population and exploitation in public health. In: Health and Social Work. ISSN 13336-9326. Vol. 12, No 1, p. 25-33.

10. WORLD HEALTH ORGANIZATION (2016) Assessment of The Impact of a Public Health Product Tax. WHO Regional Office for Europe. Retrieved from http://www.euro.who.int/_data/assets/ pdf_file/0008/332882/assessment-impact-PH-tax-report.pdf?ua=1.

11. WORLD HEALTH ORGANIZATION (n.d.) Data and statistics. Retrieved from World Health Organization: Regional Office for Europe: http://www.euro.who.int/en/ health-topics/noncommunicable-diseases/ obesity/data-and-statistics.

12. WORLD HEALTH ORGANIZATION (n.d.). Obesity. Retrieved from World Health Organization: Regional Office for Europe: http:/www.euro.who.int/en/health-topics/ noncommunicable-diseases/obesity/obesity 